\title{
PENGARUH STRATEGI VALUE, SIZE DAN MOMENTUM TERHADAP EXCESS RETURN DI INDONESIA
}

\author{
Gleny dan William Tjong
}

\begin{abstract}
The purpose of this research is to investigate the impact from the strategies that used by investors in Indonesia, such as value, size and momentum strategy. Sample data is a monthly data of 100 non-financial individual stocks which fulfill the requirement, from July 2006 - December 2010 and use 12 months holding period. This research also use ARCH method to test heteroscedasticity and VIF method to test multicolinearity. The outcome form this research is value strategy based on book to market ratio, size strategy based on market capitalization and momentum strategy based on past six months price are not significant in Indonesia. This can be happened because of the depreciation in Indonesia currency and crisis years. In addition, Indonesia is one of emerging market in Asia, so that some of the information must be difficult and make imperfect market.
\end{abstract}

Kata kunci: Book to Market, Market Capital, Momentum, Regresi Berganda.

Seiring berjalannya waktu, dunia investasi makin diminati oleh banyak investor khususnya dalam investasi keuangan. Banyak investor yang mencoba mencari celah dalam melakukan investasi, Salah satunya adalah dengan investasi di pasar yang sedang berkembang. Terbukti di Indonesia selama tahun 2012, penanaman modal oleh asing di bursa saham mencapai 58\% dari transaksi BEI, bahkan di tahun 2013 awal mampu mencapai nilai transaksi sebesar Rp. 2,4 triliun (Financetodayindonesia.com). Tak hanya itu saja, Indonesia juga mengalami pertumbuhan ekonomi sebesar 6,3\% selama tahun 2012 (www.Tribunenews.com). Hal ini mampu membuktikan bahwa negara yang sedang berkembang khususnya di Indonesia mampu menarik investor asing.

Dunia investasi dalam bidang pasar modal di Indonesia sangat diminati oleh para investor baik dalam dan luar negeri. Selain alasan keadaan global yang sudah mulai pulih, tingkat dari return yang ada tentu memberikan dampak tersendiri. Faktor return dan juga harga saham memiliki pengaruh terhadap minat dari investor untuk melakukan investasi di dunia pasar modal. Dapat dilihat bunga deposito pada tahun 2012 adalah 5\% - 5,75\% (www.bisniskeuangan.kompas.com) dan juga inflasi Indonesia pada akhir tahun 2012 sebesar 4,3\% (www.bi.go.id). Dapat dilihat bahwa bunga deposito tidak jauh dari inflasi dan hal ini mengakibatkan deposito bukan lagi

jsh Jurnal Sosial Humaniora, Vol 7 No.2, November 2014 
investasi yang menarik. Memang pada dasarnya bahwa deposito merupakan investasi yang hampir tidak memiliki resiko (risk free) dibandingkan dengan investasi pada saham yang memiliki resiko. Dari sisi investor luar negeri dapat dilihat pertumbuhan Indonesia mencapai $6,3 \%$. Hal ini menjadikan sinyal positif bagi investor asing.

Dalam melihat asumsi model CAPM yang ada maka dimungkinkan bahwa model tersebut tidak realistis seperti pada keadaan di pasar. Hal ini dapat dilihat dengan asumsi - asumsi yang ada pada CAPM tidak realistis. Dengan demikian maka investor harus mencari alat analisa lain yang dapat dijadikan strategi dalam melakukan investasi. Beberapa penelitian sebelumnya yang dilakukan Fama dan French (1992) dan juga Jegadeesh dan Titman (1993) dapat membuktikan bahwa adanya hubungan return dengan beberapa faktor lainnya seperti dengan value, size dan momentum effect. Sehingga dengan demikian maka investor dapat melihat faktor - faktor tersebut untuk dijadikan analisa dalam melakukan investasi. Sebagai gambaran dimana value dapat digambarkan berdasarkan book to market ratio, size yang berdasarkan market capital ataupun momentum yang berdasarkan harga historis dari enam bulan terakhir.

Dalam penelitian ini akan dibahas adalah apakah adanya hubungan strategi value, size dan momentum terhadap excess return di Indoensia. Ditambahkan bagaimana pergerakan nilai tukar rupiah terhadap US Dollar selama periode penelitian berlangsung.

Tujuan dari penelitian ini adalah memahami dan juga mengetahui apakah excess return yang ada dipengaruhi strategi value, momentum dan juga local size effect, khususnya di Indonesia. Melihat volatilitas mata uang Indonesia sebagai negara berkembang.

Negara berkembang merupakan negara yang memiliki perkembangan ekonomi dan pembangunan yang cukup cepat dengan memiliki pendapatan perkapita yang tergolong rendah dan kurang dewasanya dalam pasar modal negara tersebut (www.emergingmoney.com). Negara berkembang ini sering dilirik oleh investor untuk mengalokasikan dananya. Terlebih beberapa tahun belakangan ini dimana negara - negara yang sedang berkembang ini justru menjadi penguat pasar global. 
Berita yang beredar menunjukan bahwa negara ASEAN, Asia Timur dan Pasifik dianggap mampu untuk menopang ekonomi secara global dengan melihat pertumbuhan yang ada (www.vibiznews.com). Terlebih kepercayaan dari Bank Dunia akan kekuatan ekonomi yang dimiliki Cina menjadi pengerak ekonomi secara global pada tahun 2013(www.koran-jakarta.com). Namun, untuk beberapa investor yang tidak suka dengan resiko, pasar yang sedang berkembang cenderung memiliki resiko yang lebih besar. Beberapa resiko yang dihadapi oleh investor ketika melakukan investasi di negara berkembang (Papaioannou dan Tsetsekos 1997 , 2023) : macroeconomic policy, small capitalization, liquidity dan regulations.

Regresi berganda atau yang biasa disebut dengan multiple regression merupakan salah satu bentuk model yang memiliki lebih dari satu variabel explenatori yang menpengaruhi $y$ sebagai dependen variabel ( Lim et al. 2012,168). Dapat ditambahkan bahwa dependen variabel yang ada sangat tergantung dengan variabel explanatory atau independen variabel itu sendiri.

Dalam beberapa kasus model ekonomi regresi berganda sering terjadi . Hal ini didukung oleh Nachrowi dan Usman $(2006,91)$ bahwa dengan menggunakan banyak dari variabel bebas yang ada akan semakin tinggi pula dengan kekuatan yang dimiliki regresi tersebut untuk menjelaskan variabel dependen. Dengan kata lain bahwa dengan menggunakan variabel independen yang semakin banyak akan menyebabkan residual atau error tersebut semakin kecil.

Dalam melakukan regresi secara linear berganda juga menggunakan metode dari pada Ordinnary Least Square (OLS). Hal ini tetap bertujuan agar residual yang ada pada model tetaplah terkecil.

Dalam melakukan regresi berganda ini juga perlu untuk memperhatikan beberapa hal yang ada. Menurut buku yang dituliskan oleh Lim et al. $(2012,174)$ dalam melakukan regresi berganda ini harus memperhatikan hal - hal seperti residual yang memiliki zero mean, homoskedastik, residual yang ada tidak berkorelasi dan memiliki residual yang berdistribusi secara normal.

Momentum menurut Hersh Shefrin $(2007,76)$ adalah bagaimana portfolio yang lemah cenderung untuk tidak memiliki performa yang baik dan sedangkan portfolio yang unggul akan cenderung memiliki performa yang baik. Momentum 
juga merupakan fenomena yang ada dalam pergerakan saham yang berpengaruh terhadap harga saham di masa sekarang dan di masa yang akan datang. Sebagai contoh harga saham yang tinggi saat ini maka akan tinggi pula dimasa yang akan datang (W. de Groot et al.2012). Selain itu, momentum effect dapat didefinisikan sebagai kecenderungan saham yang memiliki performa yang buruk dan saham yang memiliki performa yang baik dalam satu periode sampai berkelanjutan yang memiliki performa yang abnormal selama periode tersebut (Bodie et al.2008, 371).

Momentum ini kerapkali dihubungkan dengan perilaku keuangan. Sebagai contoh dari perilaku keuangan adalah dimana informasi yang beredar di pasar akan membawa dampak kepada investor dan menjadikan harga saham yang ada menjadi underreaction atau overreaction. Ketika terdapat informasi yang baik beredar dipasar maka akan menjadi overreaction dan investor melakukan pembelian dan harga menjadi naik (Hersh Shefrin 2007,77). Jika underreactiion dan overreaction dilakukan dalam jumlah yang besar akan menyebabkan terjadinya fenomena momentum.

Momentum ini dapat dijadikan strategi dalam melakukan investasi yang dikenal dengan momentum investment strategy. Dimana dalam melakukan strategi ini investor cenderung untuk mengkoleksi saham - saham yang dianggap baik dan menjual saham - saham yang dianggap sebagai buruk. Saham yang bisa dianggap sebagai unggul adalah saham - saham yang memiliki performa baik dimasa lalu dan sebaliknya saham yang dianggap buruk adalah saham yang memiliki performa yang rendah pula. Dalam melakukan momentum strategy ini diperlukan data historis yang ada seperti 3,6 dan juga 12 bulan. Sehingga dalam jangka waktu tersebut dapat dilihat performa masing - masing saham.

Value merupakan nilai yang didapatkan dari internal perusahaan dengan didapat dari laporan keuangan yang ada. Sehingga dengan menggunakan rasio dan laporan keuangan sebelumnya, nilai dari perusahaan tersebut dapat diketahui. Dengan tingginya rasio yang ada maka akan mendatangkan return yang tinggi pula, hal ini yang disebut dengan value effect (W. de Groot et al.,2012).

Book-to-market ratio adalah salah satu yang digunakan dalam melakukan valuasi perusahaan. Hal ini kerap kali dilakukan oleh investor untuk mengetahui 
nilai yang sebenarnya pada suatu perusahaan dibandingkan dengan harga yang terdapat dipasar. Jika harga saham yang terdapat pada pasaran lebih rendah dibandingkan dengan harga buku sehingga menyebabkan rasio yang tinggi maka saham tersebut undervalued dan sebaliknya ketika harga yang ada dipasaran lebih tinggi daripada harga yang terdapat di buku maka harga saham tersebut dianggap overvalued sehingga memiliki rasio yang rendah pula.

Dalam penelitian yang dilakukan oleh Fama dan French (1992) menunjukan bahwa dengan rasio book-to-market yang tinggi maka akan menjadi resiko karena nilai pasar yang rendah dan dapat didefinisikan sebagai perusahaan yang bermasalah. Namun dilain hal, perusahaan yang memiliki rasio yang tinggi akan mencerminkan keadaan pasar yang tidak efisien. Hal ini pun akan menimbulkan resiko bagi investor.

Size dari suatu perusahaan ditentukan dari market capitalization of equity. Investor biasanya akan melihat market capitalization sebagai salah satu indikator selain dari pada fundamental perusahaan itu sendiri. Penelitian yang ada sebelumnya menunjukan bahwa dengan rendahnya market capitalization maka akan mendatangkan return yang lebih tinggi dibandingkan dengan perusahaan yang memiliki market capitalization yang tinggi (Groot et al.,2012).

Dalam hubungan antara size dan juga harga saham yang ada dapat dilihat dari nilai yang ada apakah undervalued atau overvalued. Hal ini dilihat antara harga yang ada dipasar dan juga harga intrinsik saham tersebut. Jika harga yang ada adalah undervalued maka harga intrinsik yang ada dipasar masih dibawah harga buku dan cenderung menjadi tinggi. Sebaliknya, saham yang overvalued memiliki harga yang sudah tinggi dipasar dari pada harga intrinsik dari saham itu sendiri dan harga yang ada akan menjadi rendah kemudian yang disebabkan investor yang menjual saham tersebut.

Penelitian yang dilakukan Zarowin (1990) menambahkan dari teori size itu sendiri. Seperti bahwa adanya kecenderungan saham yang memiliki performa yang kurang baik memiliki kemungkinan menjadi baik, sebaliknya bahwa perusahaan yang memiliki performa baik tidak cenderung untuk menjadi saham yang kurang baik. Hal ini dapat dikaitkan dengan size yang dimiliki oleh perusahaan tersebut. 
Dalam kinerja perusahaan yang kurang baik memiliki size yang lebih kecil dibandingkan perusahaan yang memiliki performa yang baik.

\section{Metodologi}

\section{Data Penelitian}

Perusahaan yang dimasukan sebagai sampel penelitian adalah semua perusahaan kecuali perusahaan yang bersifat finansial (industri bank, industri sekuritas dan juga asuransi). Hal ini disebabkan karena perusahaan yang bersifat finansial tersebut memiliki leverage yang besar sehingga data yang ada tidak dapat menggambarkan nilai perusahaan yang sesungguhnya. Selain itu, perusahaan yang ada harus memiliki laporan keuangan dan rasio yang lengkap di dalam IDX Statistic dan juga menunjukan book to market ratio yang positif dari Juli 2006 - Desember 2010. Selain data harga saham dan juga laporan keuangan individual perusahaan secara bulanan, penelitian ini didukung dengan index domestik, 1 bulan T-bill rate dan juga pergerakan nilai tukar mata uang domestik dengan negara yang sudah maju. Satu bulan dari T-bill rate ini diambil sebagai indikator yang menggambarkan risk free dan dipilih karena dianggap dapat digunakan sebagai acuan secara internasional. Selain itu didukung juga karena dalam penelitian ini mengambil asumsi negara yang menjadi landasan adalah Amerika Serikat. Hal ini dikarenakan Amerika dianggap sebagai salah satu negara yang memiliki hard currency pula. Dimana harga saham yang ada dikonversikan ke dalam US Dollar lalu dilakukan perhitungan selanjutnya untuk mendapatkan return. Hal ini dikarenakan agar dapat dilihat oleh investor dari luar Indonesia.

\section{Pembentukan Portfolio}

Dalam melakukan penelitian ini, peneliti memerlukan portfolio yang berisi saham yang ada sesuai kriteria dan yang sudah ditentukan dari tahun Juli 2006 Desember 2010. Data harga yang ada pada masing - masing saham yang ada dalam satuan Rupiah maka dari itu dikonversikan dahulu kedalam US Dollar.

Awal dari pembentukan portfolio ini sendiri didasarkan pada strategi yang ada. Dalam hal ini diambil dari $20 \%$ saham yang terbaik berdasarkan strategi yang 
ada dengan membandingkannya dengan index portfolio yang ada dan dijadikan label sebagai top portfolio. Selain itu 20\% saham yang kurang menarik dijadikan label sebagai bottom portfolio. Namun pada umumnya, penelitian ini di fokuskan pada top portfolio. Top portfolio ini juga dikurangi dengan index untuk menemukan top minus index (TMI) yang menjadi variabel dependen. Top portfolio juga didasari berdasarkan strategi yang ada, seperti value strategy, size strategy dan juga momentum strategy yang akan dijelaskan selanjutnya.

Pada penggunaan dari strategi value yang didasari oleh book to market ratio. Dalam pembentukan portfolio untuk strategi ini mengurutkan dari perusahaan yang memiliki book to market ratio yang tinggi sampai terendah. Dengan demikian dapat ditemukan $20 \%$ perusahaan yang memiliki rasio yang paling tinggi kemudian dijadikan sebagai top portfolio berdasarkan strategi value. Dimana $20 \%$ terbawah dari rasio yang ada dijadikan bottom portfolio. Dengan mengetahui perusahaan perusahaan yang memiliki rasio tertinggi dan terendah itu dapat dikalkulasi tingkat pengembalian per bulan lalu diakumulasi selama 12 bulan. Hal ini bertujuan untuk melihat jangka panjang dan juga efektifitas dalam transaction cost.

Pada penggunaan strategi size didasari oleh market capitalization. Menggunakan pembentukan dengan membuat portfolio yang berdasarkan small market capitalization dan big market capitalization. Dalam small market capitalization ini juga disebutkan sebagai top portfolio dan big market capitalization merupakan bottom portfolio. Langkah awal yang dilakukan dengan mengurutkan market capitalization dari terendah hingga tertinggi. Lalu dalam melakukan pembuatan portfolio small market capitalization ini didasarkan kepada $20 \%$ perusahaan yang memiliki kapitalisasi terendah dan portfolio dari big market capitalization yaitu dengan $20 \%$ terbesar. Langkah yang dilakukan kemudia mengkalkulasi return setiap bulannya dan dilakukan akumulasi selama 12 bulan dalam bentuk US Dollar.

Dalam pembentukan portfolio untuk strategi momentum digunakan cara yang sama. Dimana langkah awal mengurutkan dari akumulasi tingkat pengembalian dalam US Dollar enam bulan terakhir dari yang paling besar hingga yang terkecil. Dimana $20 \%$ tterbesar dijadikan top portfolio dan $20 \%$ terendah 
dijadikan bottom portfolio. Setelah mengetahui saham - saham yang ada dalam top dan bottom portfolio maka dilakukan perhitungan untuk tingkat pengembalian bulan - bulan berikutnya yang kemudian diakumulasi selama 12 bulan.

Dalam pembentukan dari portfolio ini sendiri dilakukan pada setiap bulannya dan menggunakan 12 bulan sebagai holding period hal ini berguna untuk melihat jangka panjang dan juga efektifitas dalam waktu. Dalam portfolio ini, return yang ada dikalkulasi dan menggunakan USD sehingga dapat dilihat dari sisi investor dari luar Indonesia.

Dalam melakukan penelitian melihat dari acuan pengembangan dari model Fama- French sebagai berikut :

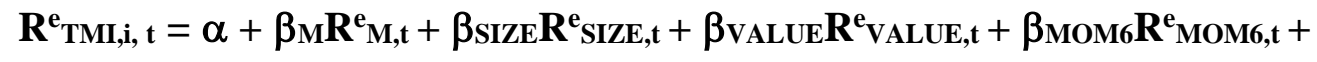
$\varepsilon t$

Notasi :

$\mathrm{R}_{\mathrm{TMI}, \mathrm{i}, \mathrm{t}}=$ return dari Top Minus Index

$$
\text { ( } \mathrm{i}=\text { size, value dan momentum) }
$$

$\alpha=$ intersep dari regeresi

$\mathrm{RM}=$ return top portfolio minus 1 bulan T-bill

SIZE = return small market capitalization portfolio minus big market capitalization portfolio

VALUE = return high book-to-market ratio portfolio minus low book-to-market ratio portfolio

MOM6 = return high past 6 months return portfolio minus low past 6 monthes return portfolio

$e=$ error term

\section{Variabel Penelitian}

Berikut ini merupakan penjabaran dari variable yang terikat maupun variable yang bebas :

(1). Variabel terikat (dependent variabel) 
Variabel yang terikat adalah TMI yang merupakan tingkat pengembalian (return) dari top portfolio minus index. Top portfolio yang dimaksud adalah top portfolio yang ada berdasarkan strategi value, size dan momentum yang telah dijelaskan sebelumnya lalu dikurangi dengan index.. Sehingga, variabel yang ada ini ditentukan oleh variabel yang tidak terikat seperti VALUE, MOM6 dan SIZE. Nilai dari variabel terikat ini sangat bergantung kepada variabel lain yang tidak terikat dan nilainya ditentukan dari variabel yang tidak terikat tersebut.

(2). Variabel bebas

\subsection{VALUE}

Variabel yang tidak terikat yang pertama adalah nilai dari sebuah perusahaan dari saham yang ada. Hal ini dilihat dari rasio yang ada seperti book to market ratio. Data yang ada tersebut diurutkan dari book to market ratio paling tinggi sampai paling rendah. Sehingga memiliki arti untuk mengetahui nilai dari masing - masing perusahan yang terdaftar di bursa. Dilakukan perhitungan untuk pembentukan portfilio dimana $20 \%$ tertinggi dijadikan top portfolio dan $20 \%$ terendah dijadikan bottom portfolio. Kemudian dilakukan perhitungan tingkat pengembalian pada masing - masing portfolio yang diakumulasikan selama 12 bulan. Perhitungan selanjutnya dengan mengurangi dari top portfolio dengan bottom portfolio yang dijadikan variabel VALUE.

\subsection{MOM6}

Variabel yang tidak terikat berikutnya adalah momentum. Momentum ini digambarkan seperti kondisi trend harga saham yang akan sama sebelum dan setelah periode yang telah ditentukan. Sebagai contoh dimana trend harga saham sebelum periode tertentu positif (naik) maka setelah periode tersebut akan menjadi naik. Hal ini dikenal dengan momentum. Dalam hal ini digunakan 6 bulan sebelumnya. Dimana diambil $20 \% 6$ bulan terakhir yang memiliki tingkat pengembalian lebih tinggi (top portfolio) dan $20 \%$ yang memiliki tingkat pengembalian rendah (bottom portfolio). Hal ini dijadikan dasar sebagai perhitungan dalam penentuan saham saham yang ada dalam top dan bottom portfolio. Lalu mengakumulasikan tingkat pengembalian 12 bulan berikutnya pada masing - masing portfolio. Setelah 
terbentuk top portfolio dikurangi dengan bottom portfolio untuk dijadikan variabel dari MOM6.

1.3. SIZE

Variabel yang lain adalah size atau ukuran dari perusahaan sendiri yang ditentukan dari modal dari market capital masing - masing perusahaan tersebut. Dilakukan pengurutan secara ascending. Sehingga mengurutkan data dari kapitalisasi pasar kecil sampai yang besar yang kemudian diambil 20\% terkecil dan terbesar kemudian dijadikan top dan bottom portfolio. Setelah mengetahui akan dasar dari saham saham yang ada didalam portfolio dilakukan perhitungan tingkat pengembalian pada bulan - bulan berikutnya dan mengakumulasi selama 12 bulan. Langkah selanjutnya dengan mengurangi top portfolio dengan bottom portfolio dan dijadikan variabel pada SIZE.

\section{Uji Asumsi Klasik}

\section{Uji Heteroskedastisitas}

Heteroskedastisitas ini merupakan keadaan dari varian yang ada tidak konstan atau pun berubah - ubah dan juga hal ini mungkin saja terjadi pada regresi yang tidak saja majemuk melainkan juga sederhana (Nachrowi dan Hardianus Usman 2006,109).

Dalam melakukan pengujian ini melihat apakah adanya perbedaan dari variance yang ada dari pengamatan yang ada. Dalam melakukan pengujian ini dilakukan dengan melakukan dengan model ARCH (Autoregressive Conditional Heteroskedasticity). Model ini dikembangkan oleh Engel dan digunakan dalam keadaan variance yang ada bersifat fluktuatif (Manurung dan Sarangih 2005,356). Hal ini dapat dikaitkan dengan masalah heteroskedastisitas. Dimana yang telah diterangakan sebelumnya bahwa heteroskedastisitas merupakan keadaan dimana variance yang ada berubah. Sehingga hipotesis nolnya adalah tidak ada efek dari ARCH.

\section{Uji Multikolinearitas}

Menurut Nachrowi dan Hardinus Usman (2006,95), multikolinearitas merupakan adanya hubungan yang bersifat linier antara variabel bebas yang ada. 
Dalam melakukan penelitian, pengujian ini dianggap penting agar mengetahui hubungan yang ada antara variabel bebas yang ada, apakah berkorelasi atau tidak. Menurut Gujarati $(1988,284)$, hubungan yang linear akan terjadi dengan kondisi :

$$
\lambda_{1} X_{1}+\lambda_{2} X_{2}+\ldots \ldots+\lambda_{k} X_{k}=0
$$

dimana $\lambda_{1}, \lambda_{2}, \lambda_{\mathrm{k}}$ merupakan nilai yang konstan dan tidak semuanya bernilai nol.

Multikolinearitas yang ada juga ditemukan dalam variabel $\mathrm{X}$ yang tidak memiliki korelasi tetapi tidak sempurna, dapat digambarkan :

$$
\lambda_{1} X_{1}+\lambda_{2} X_{2}+\ldots \ldots+\lambda_{k} X_{k}+v_{i}=0
$$

dimana $\mathrm{v}_{\mathrm{i}}$ merupakan stochastic error term.

Dalam melakukan pengecekan terhadap multikolinearitas digunakan Variance Inflating Factor (VIF). Dengan menggunakan nilai dari VIF tersebut dapat mengetahui ada atau tidaknya korelasi antara variabel yang ada. Nilai VIF sendiri adalah (Mandala 2001,272):

$$
\mathrm{VIF}=\frac{1}{\left(1-r^{2} \mathrm{j}\right)}
$$

Dengan $R^{2}$ merupakan koefisien determinasi antara variabel bebas ke - j dengan variabel bebas lainnya.

Untuk menafsirkan penilaian dalam kolinearitas, Nachrowi dan Usman $(2006,102)$ menyatakan bahwa dengan VIF > 10 menunjukan adanya gejala multikolinearitas. Jika hasil yang ditemukan kurang dari sepuluh, maka tidak ditemukan gejala multikolinearitas.

\section{Hasil dan Pembahasan}

Pengujian dalam penelitian ini bertujuan untuk melihat dari strategi value, size dan momentum di Indonesia.Variabel dependen dari masing - masing strategi adalah Top Minus Index (TMI) yang dijelaskan oleh RM, VALUE, SIZE dan MOM6.

Dari tabel 1 dapat digambarkan bahwa menurut strategi value, variabel yang signifikan hanya ditunjukan dengan variabel RM yang mencerminkan top portfolio dikurangi dengan satu bulan T-bills. Hasil probabilitas RM menunjukan 0,0034 yang 
berarti lebih kecil jika dibandingkan dengan alpha lima persen dan ditambah dengan memiliki pengaruh positif yang ditunjukan dengan koefisien 0,888. Dapat diambil kesimpulan bahwa variabel RM dapat mempengaruhi positif terhadap variabel TMI. Setiap kenaikan satu persen pada RM maka akan berpengaruh sebesar $0,888 \%$ pada TMI.

Regresi yang ada dalam strategi value memiliki $R$-square sebesar 0,526. Hal ini menunjukan bahwa variabel independen yang ada seperti : RM, VALUE, SIZE dan MOM6 dapat menjelaskan dependen variabel yaitu TMI sebesar 52,6\%. Secara keseluruhan model ini menunjukan hasil yang signifikan dengan $\mathrm{F}$ statistik yaitu 0,000086 yang dimana lebih kecil dari pada lima persen.

Berdasarkan strategi size pada tabel 2, variabel yang signifikan ditunjukan dengan variabel RM. Probabilitas yang ditunjukan adalah 0,0085 dimana lebih kecil dari pada lima persen. Koefisien yang dimiliki oleh variabel RM menunjukan hasil yang positif sebesar 0,505. Dapat digambarkan dengan kenaikan satu persen pada RM akan membawa kenaikan sebesar $0,505 \%$ pada TMI. Sedangkan intersep yang ada sebesar 0,004 pada startegi size.

$R$-square pada staregi size adalah 0,691 dan probabilitas $\mathrm{F}$ statistik adalah 0,000. Sehingga, variabel independen yang ada dapat menjelaskan dependen sebesar $69,1 \%$ dan secara keseluruhan dapatkan hasil yang signifikan yang ditunjukan dengan probabilitas yang lebih kecil dari pada lima persen. Hasil $R$-square yang ditunjukan pada penggunaan strategi size lebih baik dibandingkan dengan strategi value. Sehingga dapat ditarik kesimpulan bahwa strategi size dapat lebih menjelaskan dari pada strategi value.

Pada tabel 3 menunjukan hasil bahwa variabel RM yang ada menunjukan hasil yang signifikan. Hal ini dilihat dari probabilitasnya yang kurang dari lima persen. RM memiliki hubungan yang positif dengan TMI yang dilihat dari koefisien yang positif sebesar 0,879. Sehingga dengan kenaikan satu persen pada RM membawa kenaikan sebesar 0,879\% pada TMI.

$\mathrm{R}$ square pada strategi momentum ini menunjukan angka sebesar 0,652 dan menunjukan hasil probabilitas pada F statistik sebesar 0,000001. Dapat diambil kesimpulan bahwa variabel independen pada strategi momentum ini dapat 
menjelaskan variabel dependen sebesar $65,2 \%$ dan memiliki hasil yang keseluruhan signifikan karena probabilitas F statistik yang lebih kecil dari pada lima persen.

Dari keseluruhan akan strategi yang ada dapat dilihat bahwa hasil dari $R$ square tinggi namun tidak memiliki hasil yang signifikan pada variabel independen lainnya seperti SIZE, VALUE dan MOM6. Hal ini kerapkali dapat terjadi karena dalam melakukan penelitian ini menggunakan regresi berganda. Dimana variabel RM yang mewakili dari independen variabel dapat menjadi sangat kuat dalam regresi yang ada dalam beberapa strategi. Ditambah dengan intersep yang ada pada masing masing strategi memiliki probabilitas yang lebih dari pada lima persen sehinga dipastikan strategi - strategi yang ada tidak signifikan.

Dari sisi yang lain dapat dilihat pula pada masing - masing strategi menggunakan faktor - faktor tertentu. Seperti pada starategi value menggunakan book to market ratio, hal ini yang seharusnya dipertimbangkan dalam investasi di Indonesia untuk menggunakan rasio yang lain. Hal ini didasari karena penggunaan book to market ratio tidak tepat.

Hasil penelitian ini didukung dengan penelitian yang menggunakan size cenderung memiliki observasi yang lama dan menggunakan periode jangka waktu yang lama kemudian disamping itu, dalam faktor size juga diperlukan untuk melihat transaction cost (Reilly dan Norton 2006,282). Sedangkan untuk book to market memiliki hasil yang tidak signifikan didukung oleh Jensen, Johnson dan Mercer yang mengindikasi book to market dan juga size hanya terjadi saat periode kebijakan moneter expansif (Reilly dan Norton 2006,283).

Pada gambar 1, dapat dilihat bahwa pada tahun 2008, rupiah memiliki kecenderungan untuk melemah terhadap US Dollar. Hal ini disebabkan dengan adanya krisis yang ada pada Amerika yang dikenal dengan sub-prime mortgage. Dimana adanya gagal bayar dari segi kredit kepemilikan rumah yang beruntut hingga masalah perbankan. Diawali dari Amerika,Eropa dan kemudia di Asia. T-Bill rate pada tahun 2008 khususnya pada bulan Oktober turun satu persen dibandingkan bulan sebelumnya. Dampaknya pada Indonesia adalah melemahnya rupiah pada bulan Oktober tahun 2008 yang mencapai level Rp.11.050,- kemudiab berlanjut sampai puncak tertingginya pada awal Desember 2008 yang mencapai level Rp. 
12.285,-. Hal ini dapat disikapi investor dalam dua sisi. Sisi pertama dilihat dari jangka pendek, investor yang melakukan investasi secara internasional dalam hal ini indonesia, akan menerima keuntungan dari nilai tukar rupiah yang melemah. Di sisi lain melemahnya mata uang tersebut dapat dijadikan cermin dari pada resiko negara tersebut.

Jika dihubungkan dengan penelitian yang ada, maka nilai tukar Rupiah terhadap US Dollar ini berpengaruh terhadap harga saham yang ada. Hal ini dikarenkan bahwa penelitian ini dibuat bertujuan dipandang dari sisi investor luar negeri. Dengan melemahnya mata uang di Indonesia maka investor cenderung lebih takut akan resiko dari sisi fundamental negara.

\section{Kesimpulan dan saran.}

Dalam masing - masing strategi yang ada memiliki variabel - variabel yang tidak signifikan. Hanya satu dari empat variabel yang digunakan yang menunjukan hasil yang signifikan, yaitu variabel RM (top portfolio dikurangi 1 bulan T-bill). Sehingga variabel - variabel yang lain seperti VALUE ,SIZE dan MOM6 tidak dapat mendukung dari strategi yang ada.

Hasil yang tidak signifikan ini dapat disebabkan oleh beberapa alasan :

(1). Perbedaan dalam karakteristik data ataupun observasi yang ada.

(2). Pasar yang digunakan adalah pasar Indonesia yang masih relatif tidak stabil. Hal ini menyababkan bahwa return yang merupakan hasil perhitungan dalam US dollar mengalami hasil yang tidak signifikan. Ini dapat dilihat dari nilai tukar rupiah yang masih cenderung lemah.

(3). Penggunaan negara penelitian yang minimum, yaitu dengan menggunakan negara Indonesia saja. Hasil yang signifikan untuk strategi value dan juga momentum ditemukan dengan membuat portofolio dengan menggunakan banyak negara.

(4). Keadaan krisis ekonomi yang dihadapi oleh Indonesia bahkan dunia menyebabkan volatilitas dari harga saham yang cenderung berubah.

Saran untuk penelitian berikutnya adalah: 
(1). Sebaiknya penelitian menggunakan rasio - rasio atau alat analisa lain yang dapat

mengambarkan dari strategi value,size dan momentum.

(2). Menggunakan transaction cost agar hasil yang dicapai mencerminkan kondisi pasar yang sebenarnya.

Saran untuk investor :

(1). Strategi value, size dan momentum belum dapat diterapkan di Indonesia. Hal ini menyebabkan strategi ini tidak tepat jika dilakukan di Indonesia.

\section{Daftar Pustaka}

Berk, Jonathan and Peter DeMarzo.2009.Corporate Finance The Core. United States of America : Pearson.

Bodie,Zvi, Alex Kane and Alan J. Marcus.2008.Investment and Portofolio Management, 7th edition. Singapore :McGraw Hill

2011.Investment and Portofolio Management, 9th edition. Singapore :McGraw Hill

Cakici,Nusret and Sinan Tan,2013,Size,Value and Momentum in Emerging Market Stock Return.Emerging Market Review.

Chui,Andy.C.W. and K.C.John Wei,1998,Book to Market, Firm Size and the Turn Og The Year Effect: Evidence from Pasific Basin Emerging Market.Pasific Basin Journal ,275-293.

Emerging Money,"What is the difference between a developed,emerging and frontier market?". Emerging Money online. Available from http://emergingmoney.com/bric/what-is-the-difference-betweem-a-developed-

emerging-frontier-market-anyway/ ;Internet asscessed 2 April 2013.

Fama, Eugine F., and Kenneth R. French, 1992, The Cross Section of Expected Stock Return,Journal of Finance 47,472-465

1993, Common Risk Factor in The Returns on Stock and Bonds.Journal of Financial of Economics 33,3-56.

1995. Size and Book to Mrket Factors In Earning and Returns, Journal of Finance 50,131-155.

Gujarati, Damodar N., 2003. Basic Econometrics, $4^{\text {th }}$ edition. Singapore: McGraw-Hill.

Groot, de Wilma,Juan Pang and LaurensSwinkels.2012.The Cross Section of Stock Returns In Fontier Emerging Markets.Journal of Empirical Finance 19,796-818. 
187 - Pengaruh Strategi value, Size, dan momentum terhadap Excess Return di Indonesia

Hill, R. Carter, William E. Griffiths and Guay C. Lim, 2012. Principles of Econometrics, $4^{\text {th }}$ edition. United State: John Wiley \& Sons(Asia) Pte Ltd.

Indonesiafinancetoday. "Investor Asing Akumulasi Saham Awal Tahun”.Indonesia Finance Today. Available from http://www.indonesiafinancetoday.com/read/38697/InvestorAsing-Akumulasi-Saham-Awal-Tahun ;Internet: accessed 2 April 2013.

Indonesiarecovery. "Krisis Global 2008”.Indonesia Recovery. Available from http://www.indonesiarecovery.com/krisis-keuangan-global-2008.htm; Internet: accessed 22 April 2013.

Jegadessh, Narasimhan and Sheridan Titman. 1993, Returns to Buying Winners and Selling Losers: Implications for Stock Market Efficiency. Journal of Finance, 65-91.

Kompas."Suku Bunga Bank Sama”.Koran Kompas online.Available from http://bisniskeuangan.kompas.com/read/2012/03/12/23573740/suku.bunga.bank.sama ; Internet accessed 23April 2013.

Koran Jakarta."Negara Berkembang Pergerak Utama Ekonomi Global". Koran Jakarta online. Available from http://koran-jakarta.com/index.php/detail/view01/110466; Internet accessed 22 April 2013.

Maddala, C.S., 2001. Introduction To Econometrics, $3^{\text {th }}$ edition. England: John Wiley \& Sons Ltd

Manurung. Jonni J., Adler Haymans Manurung dan Ferdinand Dehoutman Saragih.2005.Ekonometrika:Teoro dan Aplikasi.Jakarta:Elex Media Komputindo.

Nachrowi, Nachrowi D. dan Hardius Usman, 2006. Pendekatan Populer dan Praktis Ekonometrika Untuk Analisis Ekonomi dan Keuangan, Jakarta: Fakultas Ekonomi Universitas Indonesia.

Papaioannou, Michae.1997.Emerging Market PortfoliosDifersification and Hedging Strategies.United States of America: MCGrow Hill.

Reilly, Frank K. and Keith C. Brown.2006. Investment Analysis and Portfolio Management. United States of America :Thomson. , Edgar A. Norton.2006.Investment, $7^{\text {th }}$ edition. Canada:Thomson.

Ross,Stepen A., Radolph W.Wasterfield and Bradford D.Jordan, 2010. Fundamental of Corporate Finance, $9^{\text {th }}$ edition. Singaore:McGraw Hill.

Shapiro, Alan C.2005.Foundation of Multinational Financial Management, $5^{\text {th }}$ edition. United States of America:Wiley.

Shefrin, Hersh.2007.Behavioral Corporate Finance: Decision That Create Value.Singapore:McGraw Hill. 
Tribune News, “Ekonomi RI Tahun 2012 Tumbuh 63 persen”. Tribune News Online. Available from http://tribunenews.com/2012/12/29/ekonomi-ri-tahun-2012-tumbuh63-persen. ; Internet accessed 22 April 2013.

Vibiznews.” ASEAN Akan Jadi Penopang Ekonomi Global di 2013”.Vibiznews Economy \& Business.Available from http://www.vibiznews.com/2013-01-04/asean-akan-jadipenopang-ekonomi-global-di-2013; Internet accessed 22April 2013.

Zarowin, Paul,1990,Size,Seasonality and Stock Market Overreaction,Journal of Financial and Quantitative Analysis 25,113-125. Bank Indonesia.Daya Tahan Ekonomi Asia di Tengah Krisis Global.2012. 